\title{
Design of Mobile Phone Charging Power Source Using Microwave Harvesting
}

\author{
Jimmy Obira Okello ${ }^{1 *}$, Taban Habibu ${ }^{2}$
}

\author{
${ }^{1}$ Master's Student, School of Computational and Communication Sciences and Engineering, Nelson Mandela African Institution of Science and Technology, Arusha, \\ TANZANIA \\ ${ }^{2}$ Lecturer, Faculty of Technoscience, Muni University, Arua, UGANDA \\ ${ }^{\star}$ Corresponding Author: jobira32@gmail.com
}

Citation: Okello, J. O. and Habibu, T. (2020). Design of Mobile Phone Charging Power Source Using Microwave Harvesting. Journal of Information Systems Engineering and Management, 5(2), em0116. https://doi.org/10.29333/jisem/8293

\begin{tabular}{|c|c|}
\hline ARTICLE INFO & ABSTRACT \\
\hline Published: 20 May 2020 & $\begin{array}{l}\text { Mobile phones have become the most popular and the fastest means of communication as a result of the } \\
\text { substantial reduction in their prices in recent years. However, these mobile phones use rechargeable battery } \\
\text { which requires recharging, this is challenging because of the insufficient electricity supply and alternatives. In } \\
\text { Uganda, only } 28 \% \text { of the population is currently having access to electricity and less than } 7 \% \text { of the rural } \\
\text { population has electricity service. Telecommunication companies have provided network coverage to almost the } \\
\text { entire country with GSM } 2 \mathrm{G} \text { coverage at } 93 \% \text {. The mobile phone users in the rural areas are however few because } \\
\text { of inadequate electricity and burden of long distance travelling to town centers in order to charge the phone } \\
\text { batteries. This study opts for a power source alternative based on using microwave harvesting. The approach is to } \\
\text { convert the microwave signal of } 900 \mathrm{MHz} \text { frequency band from the existing telecommunication downlink } \\
\text { frequency into DC voltage. The design is based on the spiral antenna for receiving the } 900 \mathrm{MHz} \text { frequency band. } \\
\text { The design is divided into two main parts, namely antenna and charge pump voltage doubler. The spiral antenna } \\
\text { is used to harvest and convert the microwave signals into electrical signals; the charge pump helps to convert the } \\
\text { low AC to DC voltage capable of charging the battery. The simulation design is tested with Multisim simulation } \\
\text { software and the results revealed } 5 \mathrm{~V} \text { of DC power generated by means of seven stages voltage doubler. Thus, an } \\
\text { alternative source of power for mobile phone battery charging. }\end{array}$ \\
\hline
\end{tabular}

Keywords: downlink frequency, charge pump, wireless power transfer, battery charger, DC voltage

\section{INTRODUCTION}

The Mobile phone technology has become one of the dominant technologies used in almost all aspects of individual lives. It plays a major role in social, political, business and financial lives and almost everyone has resorted to using them as a quicker means of communication and carrying out business. However, the electronic components of the mobile phone require a power source. The phone manufacturers have included rechargeable batteries that fit into the mobile phones. The battery has to be recharged from time to time when they drain out and this requires a power source (Singla, 2014).

The National coverage of Electricity in Uganda is low and only $28 \%$ of the population is currently having access to electricity and less than $7 \%$ of the rural population has electricity service (Rural Electrification Agency, 2013). The Telecommunication companies, however provide network coverage to almost the entire country with global system for mobile communications (GSM) second generation (2G) coverage at 93\% (Gillwald et al., 2019). The mobile phone penetration in Uganda is 56\% (UCC, 2019), users in rural areas are still few partly because of the lack of a power source to recharge their mobile phone batteries, while urban dwellers have to deal with constant load shedding and high tariffs. This has prompted the authors of this paper to design an alternative capable of charging phone battery by means of harvesting $900 \mathrm{MHz}$ microwave signal from the existing telecommunication $2 \mathrm{G}$ downlink frequency band.

The microwave signal is an electromagnetic energy having a frequency higher than 1 gigahertz, corresponding to wavelength shorter than 30 centimeters, (Jayawant and Zope, 2014). The microwave frequency band is good for wireless transmission of signals with large bandwidth (Bell and Iskander, 2004). The bandwidth results in higher data speed in which the short wavelengths allow the use of dish antennas having manageable diameters. The antennas produce a high-power gain in transmitting applications and have excellent sensitivity and directional characteristics for reception of signals. Microwave energy can be absorbed by almost every object, but the amount absorbed varies from object to object (Patel, 2013). Microwave signal has the 
capability to penetrate solid material and is less susceptible to the effects of weather and rain making it suitable for communication of information (Patel, 2013).

Numerous researches have been done in the area of a wireless phone battery charging and alternative sources of power. However, alternative power sources suggested such as solar energy requires huge initial investment. Although spiral antenna is cheap, provides greater bandwidth with a low profile which are useful parameters in wireless mobile communication. Most researchers focused on dipole antennas, rectangular patch antennas and little attention have been put into utilizing spiral antenna for energy harvesting. The research on wireless phone charging have mostly been based on the $2.4 \mathrm{GHz}$ microwave frequency. However, little attention has been focused on using $900 \mathrm{MHz}$ downlink frequency that is used for base station signaling with mobile phones. This paper focuses its suggestion on the harvesting of $900 \mathrm{MHz}$ base station downlink frequency using a spiral antenna and converting it to direct current (DC) voltage.

The study proposed a solution based on a phone battery charging system using microwave harvesting. Where the system converts the microwave signal of $900 \mathrm{MHz}$ frequency band from the existing telecommunication base transmitting station into DC voltage and then uses the voltage to charge the battery. The design is based on the receiving antenna for the $900 \mathrm{MHz}$ frequency band in this case an Archimedean spiral antenna. The design is divided into two main parts, namely antenna and charge pump. The antenna is used to harvest and transduce the radio frequency (RF) signals into electrical signals, the charge pump voltage doubler helps to convert the low alternating current (AC) to DC voltage capable of charging the phone battery.

In summary, our contributions include:

- Design of a spiral antenna capable of extracting $900 \mathrm{MHz}$ microwave signals from the base stations downlink frequency.

- A charge pump capable of converting the output signal of the spiral antenna into DC voltage for charging a phone battery.

- Reduction of the burden of carrying spare batteries when travelling to rural areas in order to have phones working as well as elimination of using separate chargers for different mobile phones.

\section{RELATED WORKS}

\section{Microwave Technology}

Microwave is the portion of the electromagnetic spectrum with frequencies between $300 \mathrm{MHz}$ and $300 \mathrm{GHz}$ of wavelengths between $1 \mathrm{~mm}$ to $1 \mathrm{~m}$ (Jayawant and Zope, 2014). The different frequencies are grouped into bands making them utilized in various applications and fields.

\section{Applications of Microwave}

Microwave technology is currently used in a number of applications ranging from telecommunication, heating to the medical field for diagnosis, imaging and treatment. Microwave is being utilized in radar, communication systems such as police traffic guns and ship navigation to detect the range, speed, and other characteristics of remote objects (Singla, 2014). The technology has also found application in; Spectroscopy to study various chemical element spectra in physics and physical chemistry, cooking by means of a microwave oven, which passes non-ionizing microwave radiation at a frequency of about $2.45 \mathrm{GHz}$ through food causing dielectric heating primarily by absorption of the energy in water, radio astronomy to study celestial objects and astrophysical phenomena by examining the microwave radiations they emit.

Microwave technology use in communication has become common in transmitting information signals between relay stations. Although fiber-optic transmission is now popular, microwave transmission is still commonly used in the telecommunications transmission medium in Sub Saharan Africa especially GSM mobile communication networks.

\section{Antenna Systems}

An antenna is a device which radiates or receives electromagnetic waves, such as microwave signals to or from space. It consists of parameters like polarization, impedance, gain, directivity and bandwidth.

The Archimedean spiral antenna is a popular frequency independent antenna. Previous wideband array designs with variable element sizes have used the Archimedean spiral antenna as the radiating element. The spiral antenna belongs to frequency independent antennas capable of achieving fractional frequency bandwidths of 30:1 or greater. Spiral antennas have been mostly utilized in sensor applications where space constraints are a paramount consideration. A spiral antenna has circular polarization with a radiation direction perpendicular to the spiral plane with a half power beam width of about 90 degrees. The spiral antenna is considered for this study because it is cheap, provides greater bandwidth with a low profile which is typically useful in wireless mobile communication (Bell and Iskander, 2004).

\section{Frequency to Voltage Convertor}

A mobile phone always receives signal from the base station to ensure the connection between the phone and the base station is updated. This is to enable easy call setup and these signaling messages are exchanged through the downlink and uplink frequencies. These frequencies can be converted to a voltage using a frequency to voltage convertor. LM 2907 is mostly used in the conversion and this act as a switch triggering the charge pump on and off depending on the phone activity (Patel, 2013). 


\section{Wireless Charging of Mobile Phone using Microwave Harvest}

Nowadays, mobile phones have become an integral part of everyone's life and hence require frequent charging of battery owing to long duration usage. However, the charging involves plugging a physical charger on a wall socket (Marian et al., 2012). Wireless power transfer (WPT) is a means of transferring an electrical power from the source to another device without any physical connection between them (Bashi, 2017). A WPT technique of charging mobile phones without using wired chargers with the use of microwave power has been attempted in many studies. WPT technology is capable of providing a stable and controllable wireless power supply through utilizing dedicated power beacons (Huang et al., 2019). WPT is also used in long distance power transmission over microwaves, radio waves, ultrasonic waves, and the laser beam. This technology has proved to be relevant in several applications, namely; wireless sensor networks, Radio Frequency Identification (RFID), and Internet of Things (IoT) devices. In regards to the operating range, WPT is basically categorized into near-field WPT which transmits power through the coils, and far-field WPT which utilizes antennae for power radiation and reception (Huang et al., 2019). Near-field WPT technologies have proved efficiency. However, it has a very short charging range. Far-field WPT however, has a longer operating range, making it flexible and more suitable in many charging low power devices (Huang et al., 2019). Although, this long range of operation results into high path loss affecting its transmission efficiency. In addition, far-field WPT has a major safety concern due to too much electromagnetic radiation (EM) involved which is dangerous to humans. Attempts have been made to mitigate the risk of concentrating the EM radiation in the direction of the receiver via a directional antenna and energy beamforming antenna array (Huang et al., 2019).

Recently, international industry associations such as Wireless Power Consortium (WPC), Alliance for Wireless Power (A4WP) and Power Matters Alliance (PMA) were formed to come up with specifications, components and equipment in order to promote wireless charging (Kuzmin et al., 2019). Specifications such as Quality interface (Qi) are being used in many electronics gadgets like phones and electric toothbrushes utilizing Qi technology for wireless charging by using a charging pad (Huang et al., 2019). The Qi specification (v1. 2) is capable of transferring about 5watts to 15 watts of power over 5 millimeter distance by means of a frequency of $140 \mathrm{kHz}$ (Huang et al., 2019).

Wireless chargers capable of sending AC power signal to the transmitter coil have been suggested. Here when current is transferred via a coil it forms an electromagnetic field around it, this results in an oscillating magnetic field, creating current in the receiver coil (Nair and Pingle, 2016). Therefore, power is safely transferred through objects which are within the magnetic field coils. The range of power transfer can basically be increased through the addition of more coils. The receiver circuit is designed to be able to rectify AC power signal into DC power capable of charging the phone batteries (Nair and Pingle, 2016).

\section{MATERIALS AND METHODS}

\section{System Design Approach}

The study was carried out in the rural areas of Akokoro subcounty Apac district of Northern Uganda. The study looked at phone battery recharging difficulty amongst the mobile subscribers. The sample of 100 mobile subscribers responded to a series of questions and the responses were tabulated as shown in Table 1.

Table 1. Response from Mobile subscribers

\begin{tabular}{|c|c|c|c|c|}
\hline Phone Type & Recharge Times/Week & Nominal Voltage (V) & Charging Voltage (V) & Distance Travelled (Km) \\
\hline Nokia 106 & 4 & 3.7 & 5.0 & 1 \\
\hline Itel 5091 & 2 & 3.7 & 5.0 & 1 \\
\hline Itel 2163 & 3 & 4.0 & 5.2 & 2 \\
\hline Nokia 105 & 3 & 4.5 & 5.1 & 2 \\
\hline Techno T351 & 3 & 3.7 & 5.0 & 3 \\
\hline SIMI S300 & 4 & 3.7 & 5.0 & 2 \\
\hline Techno T528 & 2 & 4.0 & 5.2 & 2 \\
\hline iYou 6100 & 3 & 3.7 & 5.0 & 2 \\
\hline iYou 3010 & 3 & 4.0 & 5.2 & 3 \\
\hline Itel 2190 & 2 & 4.0 & 5.2 & 4 \\
\hline Itel 6320 & 3 & 3.7 & 5.0 & 4 \\
\hline Techno T301 & 2 & 4.0 & 5.2 & 3 \\
\hline Itel 2171 & 3 & 3.7 & 5.0 & 3 \\
\hline Average & 2.8 & 3.9 & 5.1 & 2.5 \\
\hline
\end{tabular}

From the responses tabulated in Table 1, it revealed that most people in the rural areas use simple GSM phones. It also showed that the average times of charging the phones are 2.8 times a week while the average distance travelled to find a charging point is 2.5 kilometers. The objective of the study is to provide phone battery charging power source alternative which is cheaper and reliable. The study carried out in Akokoro Sub County revealed that most subscribers owned only GSM enabled mobile phones like simple Itel, Techno, and Nokia phones.

The design of the mobile phone battery charging power source was based on the theoretical concepts of charge pump voltage doublers, microwave radiation and antenna systems, as described in Figure 1. The system comprises of an antenna, charge pump and the load or battery. 


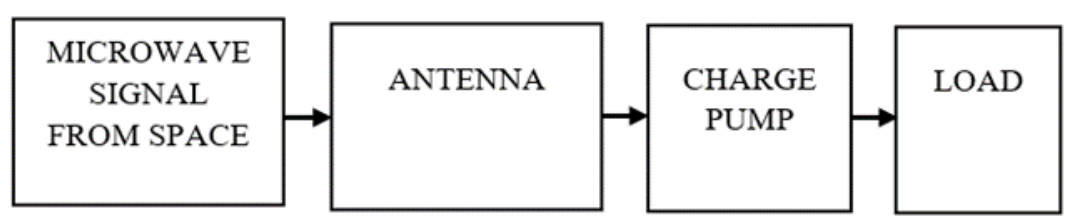

Figure 1. General system setup

\title{
Design Parameters
}

The major parameters considered during the design of this system included the followings:

\section{Frequency Band}

The GSM $900 \mathrm{MHz}$ frequency band of $890-915 \mathrm{MHz}$ for uplink to send information from the mobile phone to the base station and 935-960MHz downlink to send information from the base station to the mobile phone were used. The system was therefore designed to operate within the $935-960 \mathrm{MHz}$ frequency ranges. Therefore, the GSM 900MHz downlink mobile frequency was chosen for the design, however, the signal to be harvested by the antenna for the study were incident signals to output amplified DC energy used to charge the battery.

\section{Area of Operation}

The GSM 900MHz band was considered in the determination of the operation area because it provided the upper limit of the downlink frequency range and the receiver antenna. The radiated power of a GSM 900MHz antenna at a Base Transmitting Station (BTS) is $86 \mathrm{~dB}$ and the required antenna input power threshold is $-20 \mathrm{~dB}$.

$$
\text { Acceptable path loss is; } 86 d B-(-20 d B)=106 d B
$$

Using the theoretical calculation of the path loss;

$$
\begin{gathered}
\text { Path loss }=32+20 \log f(\mathrm{MHz})+20 \log D(\mathrm{~km}) \\
106=32+20 \log (900)+20 \log (d) \\
20 \log (d)=106-(32+20 \log (900)) \\
d=5.2 \mathrm{~km}
\end{gathered}
$$

This calculation shows that the system will be operational within a radius of $5.2 \mathrm{~km}$ from the nearest Base Transmitting Station (BTS).

\section{Battery Charging Voltage}

The nominal voltage required is larger than the charging voltage of the mobile phone battery. From the study, it is revealed that the average of the charging voltage output from the mobile phone chargers was $3.9 \mathrm{~V}$. Therefore, the nominal voltage of $5 \mathrm{~V}$ was chosen for this design.

\section{Circuit Design}

The circuit design involved converting the various components of the block diagram into detailed circuit diagrams.

\section{Charge Pump}

A charge pump is a circuit that when supplied with an input of $A C$ is able to output DC voltage typically larger than a simple rectifier would generate (Batool et al., 2012). The charge pump is made of stages of a voltage multiplier. The charge pump performs the functions of rectification and amplification of the input electrical signal from the antenna. To design a charge pump, the electronic components considered were diodes and capacitors mainly, because they are passive electronic components and therefore would not require a power supply to function (Le, Mayaram and Fiez, 2008).

\section{Determination of Values of Components Used}

The design of a receiving antenna for the $900 \mathrm{MHz}$ frequency bands in this case a spiral antenna was used and tested in simulation software.

\author{
Calculation Involved in Spiral Antenna Design \\ Frequency band (935-960MHz) \\ Lower limit $\mathrm{f}_{l}=935 \mathrm{MHz}$ \\ Wavelength $\lambda_{l}=C / f_{l}=3^{*} 10^{8} / 935^{\star} 10^{6}$ \\ $\lambda_{1}=0.32 m=C_{2}$ \\ ${ }_{\text {But }} C_{2}=2 \pi r_{2}$ \\ So, $r_{2}=C_{2} / 2 \pi=0.32 / 2 \pi=0.05 m$ \\ $\mathrm{C}_{2}=$ circumference of outer most spiral \\ Upper limit $f_{u}=960 \mathrm{MHz}$
}




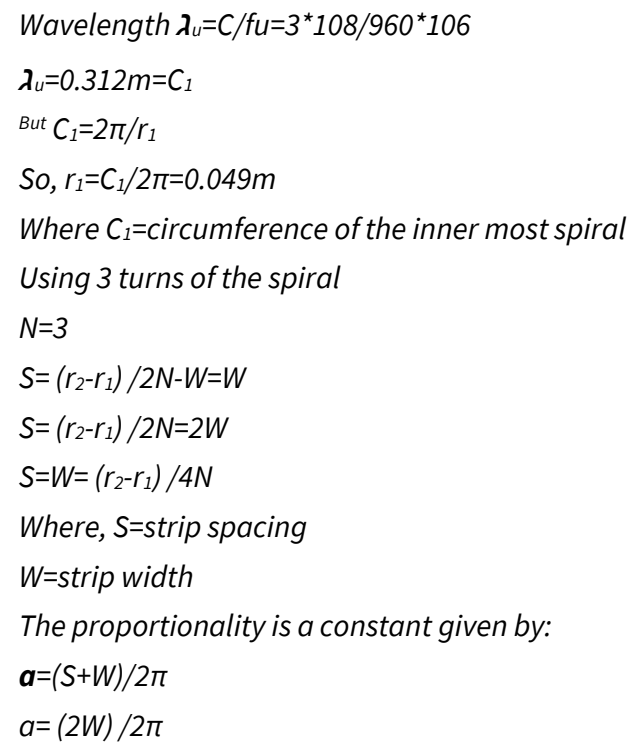

A $900 \mathrm{MHz}$ frequency was generated by a signal function generator and fed to the spiral antenna and voltage measured from its output gives a very low AC value. This was simulated and tested as shown Figure 2.

\section{RESULTS AND DISCUSSION}

In this study, the 5V DC power source was generated from GSM 900MHz microwave frequency band harvested by spiral antenna and this was achieved by seven stages of voltage doubler. Having identified the components, the circuit was tested in Multisim. Multisim is a software package used by electronic engineers and students to design and simulate electronics circuits virtually.

\section{Antenna}

The antenna functions by harvesting and transducing the RF signals into electrical signals. An appropriate antenna was designed and tested in the software by means of a multimeter. The output voltage measured from spiral was found to be about IV DC as shown in Figures 2 (a) and 2 (b).

The antenna design simulation was done for GSM 900MHz downlink frequency band. The Figures 2 (a) and 2(b) demonstrates the simulation using the $935 \mathrm{MHz}$ and $960 \mathrm{MHz}$ respectively, which corresponds to the lower and upper limits of the GSM $900 \mathrm{MHz}$ band. 


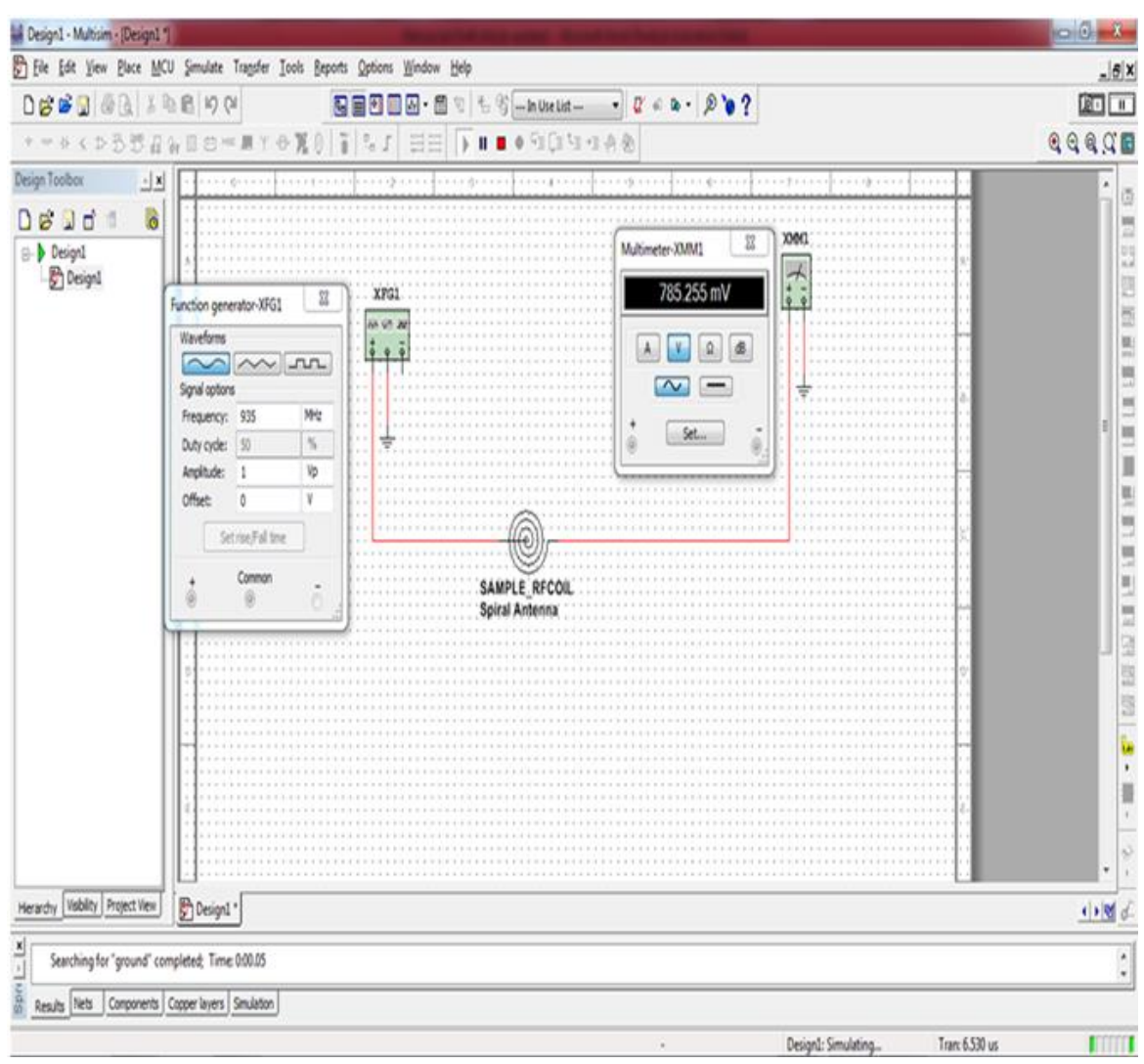

(a)

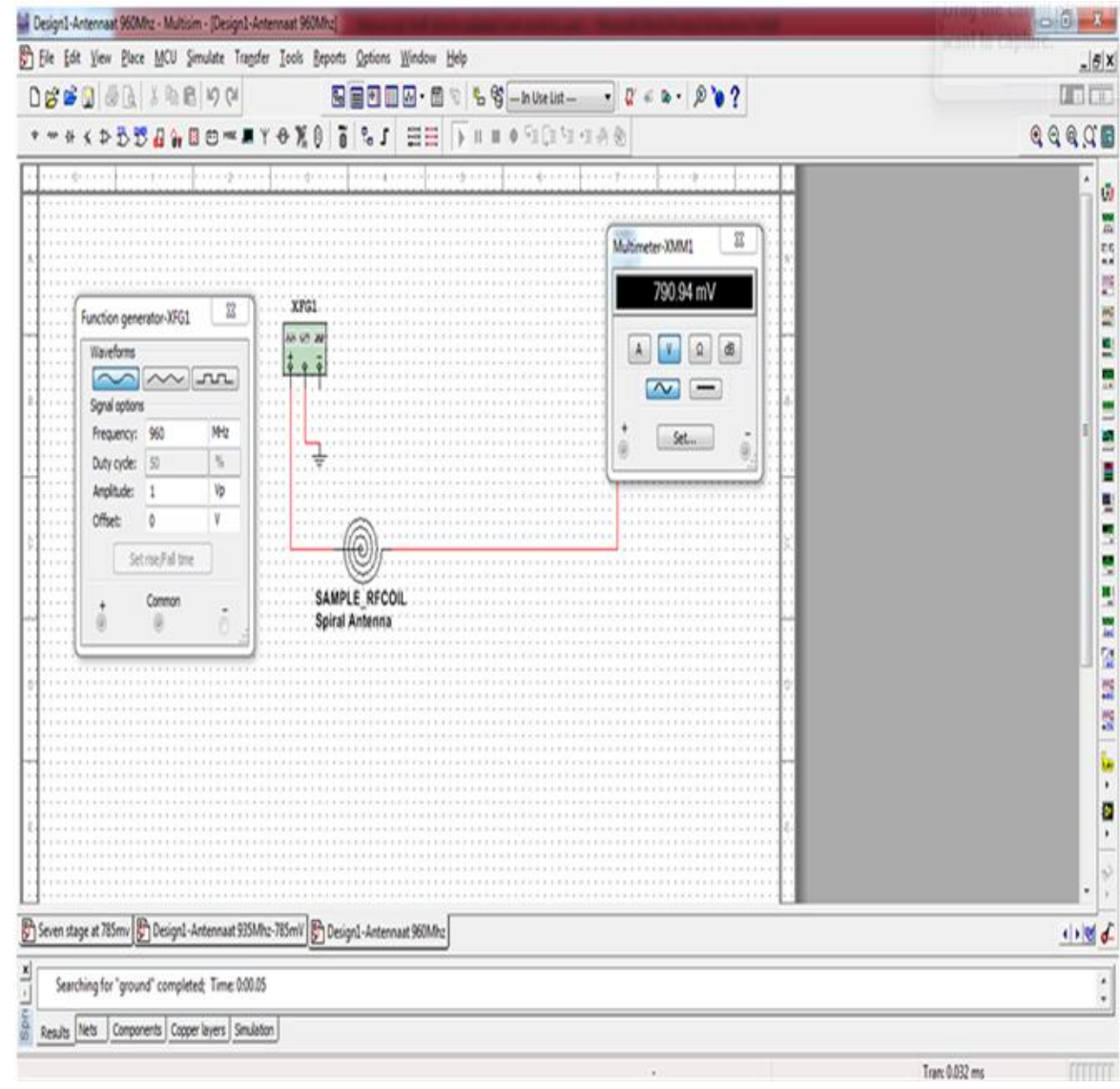

(b)

Figure 2. (a) The Antenna simulation using $935 \mathrm{MHz}$ (b) The Antenna simulation using $960 \mathrm{MHz}$ 


\section{One Stage Voltage Doubler}

The one stage voltage doubler consist of two Schottky diodes and capacitors arranged in such a way as to achieve rectification and amplification.

\section{Operation}

The voltage value of the alternating voltage source (Antenna) is about 1V. During the positive half cycle, current flows through the Schottky diode D1 forward biasing it and storing the voltage on C2. During the negative half cycle, the current flows through the Schottky diode D2 forward biasing it and voltage is stored in capacitor C1. While during the positive half cycle the charge which is stored in $\mathrm{C} 1$ is transferred to $\mathrm{C} 2$ hence doubling the voltage and the voltage doubler. The rectification is achieved through the diode action that ensures that the capacitor $\mathrm{C} 2$ is charged in the same direction for both cycles of the alternating signal from voltage source. Figure 3 illustrated the one stage voltage doubler.

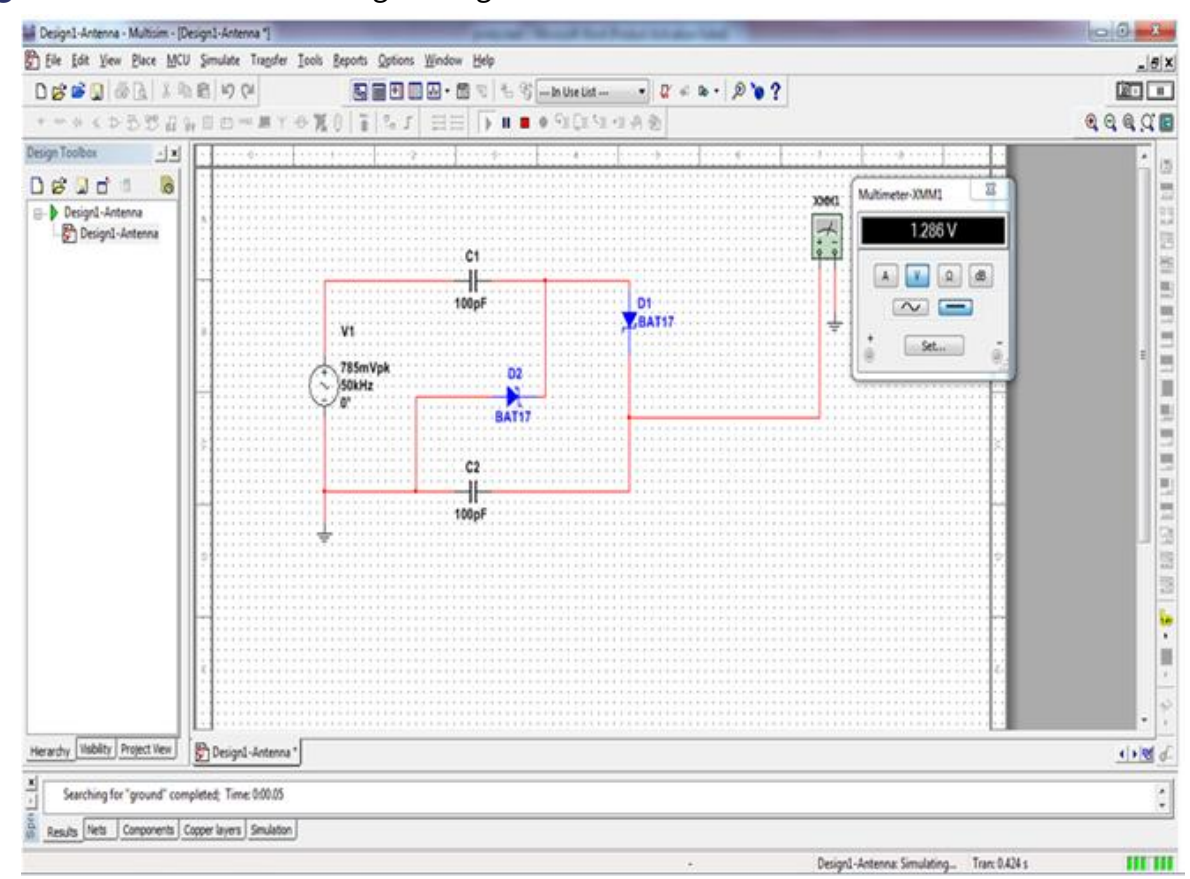

Figure 3. The one stage voltage doubler

However, the output of a single stage voltage doubler is $1.286 \mathrm{~V} \mathrm{DC}$, which is lower than the intended voltage of 5V DC.

\section{The System Design}

The intended voltage source (antenna) is measured and it is determined that the voltage input to the circuit is about $1 \mathrm{~V}$. However, the study was designed with the aim of producing an output voltage of 5V DC. The voltage output can be increased by increasing the number of stages of the voltage doublers. Seven-stage voltage doubler is considered for this study and this was simulated and tested to give 5V DC as shown in Figures $\mathbf{4}(\mathbf{a})$ and $\mathbf{4}(\mathbf{b})$. 


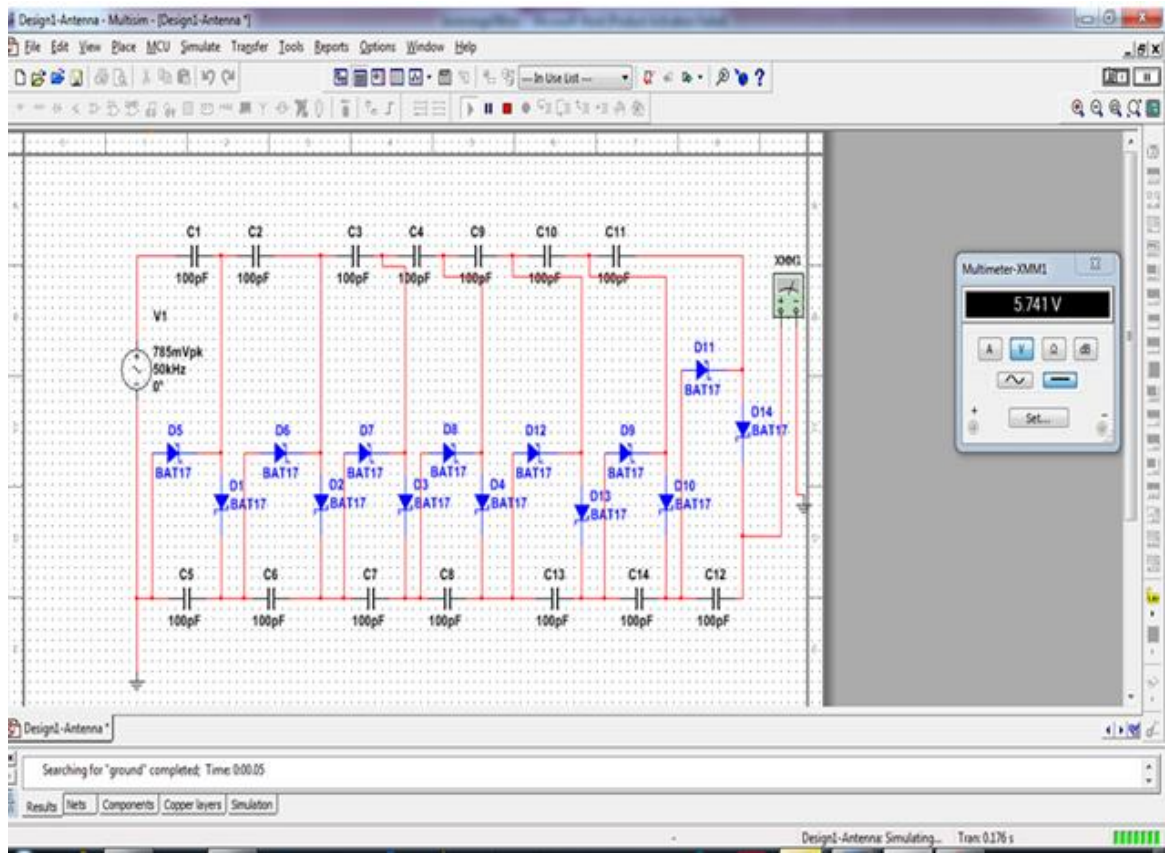

(a)

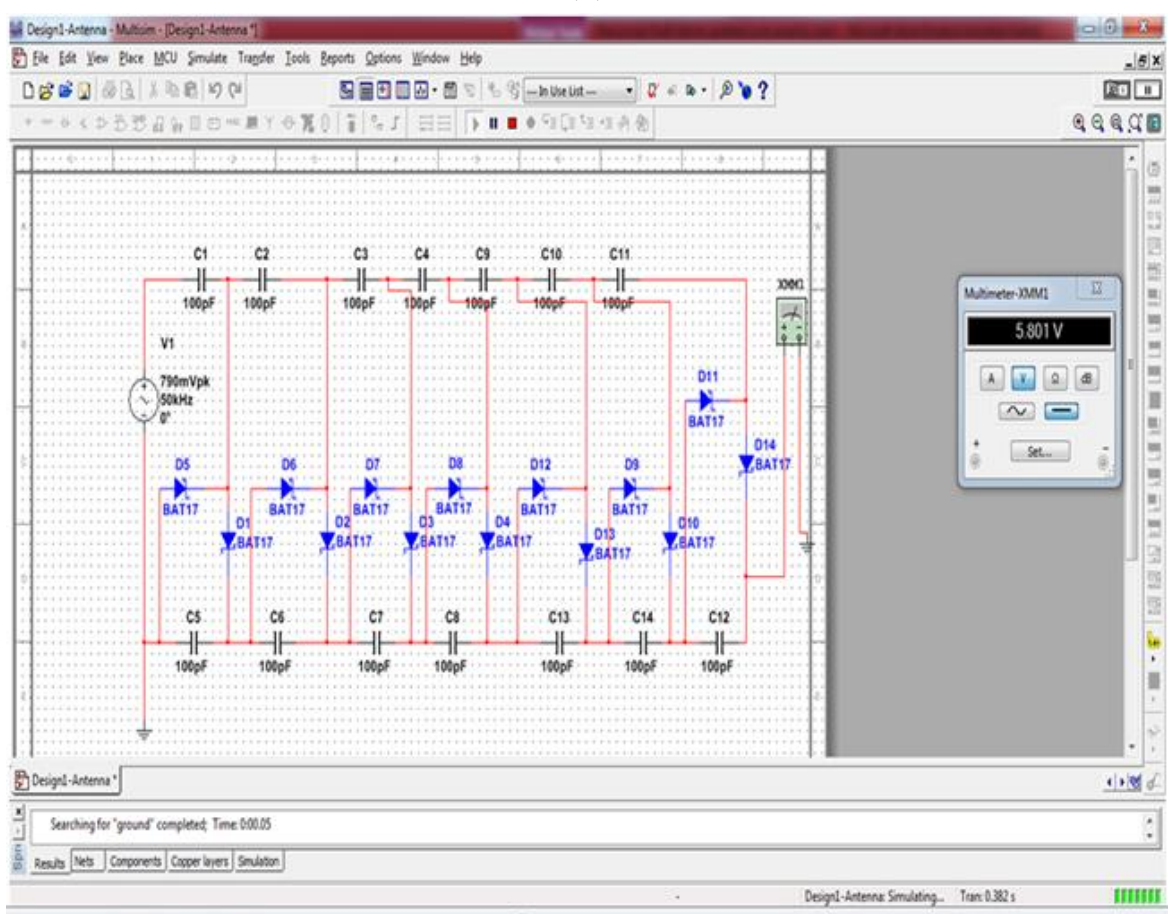

(b)

Figure 4. (a) The architectural system design using $935 \mathrm{MHz}$ (b) The architectural system design using $960 \mathrm{MHz}$

The simulation results illustrated in Figures $\mathbf{4}(\mathrm{a})$ and $\mathbf{4}(\mathbf{b})$ corresponds to the $935 \mathrm{MHz}$ and $960 \mathrm{MHz}$ frequencies respectively, and the comparison shows very little difference in the voltage generated.

\section{CONCLUSION}

The aim of the study was to explore alternative power source by means of utilizing microwave harvesting. This is because the main power supply and alternatives are still a big challenge and mostly rural population faces phone battery charging difficulties. The study focused on GSM $900 \mathrm{MHz}$ frequency band. The existing base station downlink $900 \mathrm{MHz}$ frequency was harvested by the spiral antenna and converted into 5V DC voltage by means of seven stage voltage doubler. The results were simulated and tested using Multisim simulation software. The system provided 5V DC voltage for mobile phone battery charging utilizing the microwave energy harvesting. This technique if adapted and modified by Mobile phone manufacturers can provide a cheap power charging source. The existing mains power supply is inadequate and unreliable while the alternatives like solar require huge initial investment. The system works best within the radius of $5.2 \mathrm{~km}$ from the base station due to the effect of acceptable path loss of the antenna. In future, more researches can be done to extend this radius and to utilize the $1800 \mathrm{MHz}$ and $1900 \mathrm{MHz}$ frequencies. 


\section{REFERENCES}

Bashi, I. Y. D. (2017). Wireless Mobile Phones Charging-A Comprehensive Study. International Journal of Electromagnetics and Applications, 7(2), 31-37. https://doi.org/10.5923/j.ijea.20170702.02

Batool, U., Rehman, A., Khalil, N., Islam, M., Afzal, M. U. and Tauqeer, T. (2012). Energy extraction from RF/microwave signal. 2012 15th International Multitopic Conference, INMIC 2012, 165-170. https://doi.org/10.1109/INMIC.2012.6511489

Bell, J. M. and Iskander, M. F. (2004). A low-profile archimedean spiral antenna using an EBG ground plane. IEEE Antennas and Wireless Propagation Letters, 3(1), 223-226. https://doi.org/10.1109/LAWP.2004.835753

Gillwald, A., Mothobi, Tusubira, and Ndiwalana, A. (2019). The state of ICT in Uganda. Available at: https://researchictafrica.net/2019/05/23/the-state-of-ict-in-uganda/

Huang, J., Zhou, Y., Ning, Z. and Gharavi, H. (2019). Wireless Power Transfer and Energy Harvesting: Current Status and Future Prospects. IEEE Wireless Communications, 26(4), 163-169. https://doi.org/10.1109/MWC.2019.1800378

Jayawant, A. and Zope, S. (2014). A Review Paper on Wireless charging of mobile phones. International Journal of Engineering Research \& Technology, 30-32.

Kuzmin, E. V., Platonov, S. V., Bichurin, M. I., Khavanova, M. A., Nikitin, A. O. and Petrov, R. V. (2019). The study of microwave range energy harvesting device. Journal of Physics: Conference Series, 1352(1). https://doi.org/10.1088/1742-6596/1352/1/012029

Le, T., Mayaram, K. and Fiez, T. (2008). Efficient far-field radio frequency energy harvesting for passively powered sensor networks. IEEE Journal of Solid-State Circuits, 43(5), 1287-1302. https://doi.org/10.1109/JSSC.2008.920318

Marian, V., Allard, B., Vollaire, C. and Verdier, J. (2012). Strategy for microwave energy harvesting from ambient field or a feeding source. IEEE Transactions on Power Electronics, 27(11), 4481-4491. https://doi.org/10.1109/TPEL.2012.2185249

Nair, S. and Pingle, L. (2016). Wireless charging using microwaves 1 1,2. International Journal on Theoretical and Applied Research in Mechanical Engineering, (2), 114-116.

Patel, A. (2013). Wireless Charging of Mobile Phone using Microwaves! Apurva Patel. International Journal of Scientific \& Engineering Research, 4, 1-5.

Rural Electrification Agency. (2013). Strategy and Plan Rural Electrification Strategy and Plan. Rural Electrification Strategy and PLan 2013 - 2022.

Singla, N. (2014). Wireless Charging of Mobile Phone Using Microwaves or Radio Frequency Signals. International Journal of Advanced Research in Computer Science \& Technology, 2(1), 1-3.

UCC. (2019). Broadcasting \& Postal markets Industry Report Q3. Available at: https://www.ucc.co.ug/reports/ (Accessed: 15 April 2020). 